\title{
The Impact of Airway Geometry on the Distribution of Methane Concentrations at the Outlet from a Longwall
}

\author{
Jarosław BRODNY*, Magdalena TUTAK**, Antoni JOHN*** \\ *Silesian University of Technology, Faculty of Organization and Management, Roosevelta 26-28, 41-800 Zabrze, Poland, \\ E-mail: jaroslaw.brodny@polsl.pl \\ **Silesian University of Technology, Faculty of Mining and Geology, Akademicka 2, 44-100 Gliwice, Poland, \\ E-mail: magdalena.tutak@polsl.pl \\ ***Silesian University of Technology, Faculty of Mechanical Engineering, Konarskiego 18A, Gliwice 44-100, Poland, \\ E-mail: antoni.john@polsl.pl
}

cross $^{\text {ref }}$ http://dx.doi.org/10.5755/j01.mech.24.5.21194

\section{Introduction}

In Polish hard coal mines, more than $75 \%$ of longwalls are ventilated with the $\mathrm{U}$ type system from the exploitation field borders [1]. In this system, fresh air is supplied to the longwall along the maingate and discharged from the longwall along the tailgate, also referred to as the airway (Fig. 1).

These headings are exposed to increased rock mass pressures caused by the impact of the active exploitation front that often causes a change (reduction) in the cross-section of these headings by as much as $48 \%$. This affects the safety of transportation and the performance of the ventilation system. Maintaining the efficiency and proper dimensions of these headings is therefore an important element that determines the safety of work in the area of ongoing exploitation.

During the $U$ type ventilation of longwalls (with exploitation being carried out under conditions of high methane hazard), the highest methane concentration levels are present in the intersection area between the longwall and the tailgate (the called upper corner of the longwall).

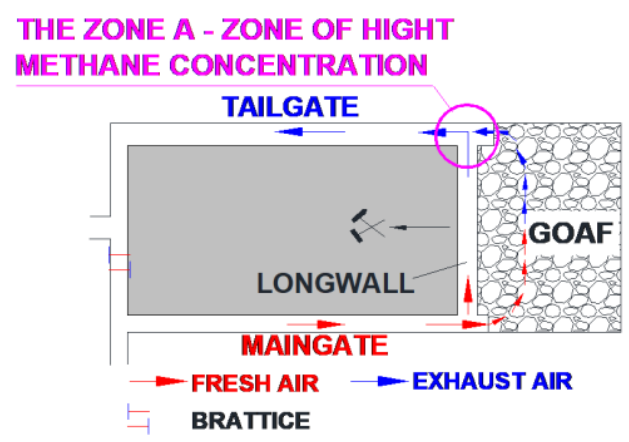

Fig. 1 The $U$ type ventilation system from the exploitation field borders

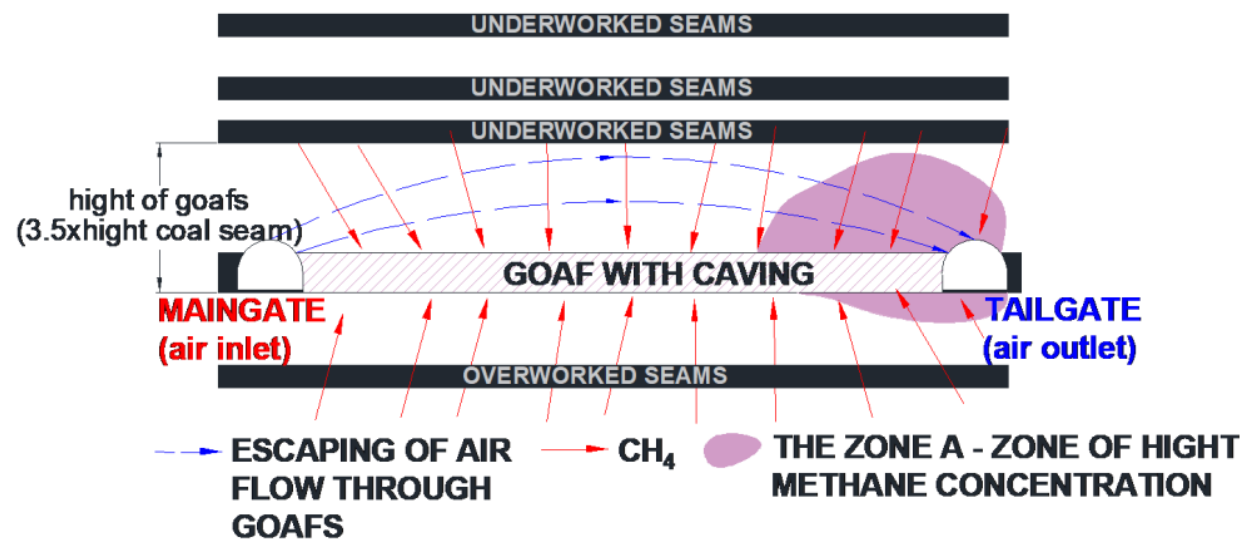

Fig. 2 The flow of methane from the goaves with caving to the longwall and the tailgate [6]

This is due to the accumulation of methane flowing from the goaves with caving and the working area of the longwall, resulting from methane emissions from the coal mined and the body of coal [1-6]. This methane then migrates along with the air stream towards the tailgate. Methane is also emitted into this space directly from the goaves through the unliquidated part of the tailgate, located behind the caving line of the longwall. The flow of methane from the goaves with caving to the longwall and the tailgate has been demonstrated in Fig. 2.
The flows presented in Figs. 1 and 2 clearly indicate that the highest methane concentration occurs in the upper corner of the longwall. Methane concentration and its distribution in this zone depend on the amount of methane flowing out of the longwall and the goaves with caving, the amount of the fresh air supplied to the longwall, and the geometry of the tailgate. This concerns the cross sectional area of the tailgate, as well as the length of its unliquidated part located behind the caving line (with the length "a"). This is because this area has the highest methane concentration levels. The length of the unliquidated part of the tailgate behind 
the caving line of the longwall may not exceed $6.0 \mathrm{~m}$, as required by mining regulations [7].

On the other hand, the cross-sections of longwall headings have a crucial influence on the provision of adequate amounts of air to the longwall, as well as on the safety of transportation. Generally, it may be assumed that the geometry of longwall headings is inseparably connected with the occurrence of the methane hazard in the area of exploitation.

From a practical point of view, it is therefore of utmost importance to determine the impact of tailgate geometry and length on the distribution of methane concentrations at the outlet from the longwall. In order to determine this impact and identify the zones with dangerous methane concentration levels (up to $2 \%$ ), model based tests were carried out for this region. The purpose of the tests was to determine the distribution of methane concentrations in the zone where the longwall is at a particularly high risk depending on the cross section of the tailgate and the length of its unliquidated part behind the caving line.

Both the cross-sectional area and the length of the unliquidated part of the airway behind the caving line during normal course of the longwall may be subject to changes, which has a direct impact on the ventilation conditions. A change in heading geometry leads to differences in aerodynamic potentials in the area of exploitation, which - in turn - impact the volume of methane emitted from the goaves with caving into the working area of the longwall. The smaller the geometry of the airway, the greater is the difference in aerodynamic potentials between the caving goaves and this airway. This may result in increased speed of methane efflux from the goaves with caving into the working area of the longwall and its upper corner.

The tests were conducted using Computational Fluid Dynamics (CFD). The related calculations were performed in ANSYS Fluent, based on the finite volume method (FVM). The analysis performed made it possible to precisely identify the concentrations levels of methane at each point in the space of the region under examination, for the boundary conditions adopted. It was conducted for four different geometries of the region in question, for a model that reflects the actual layout of headings in one of the hard coal mines. The ventilation parameters adopted in the model are real time values obtained through measurements in these headings. The parameters describing the goaves with caving were also determined on the basis of tests in real world conditions.

The methodology developed and the results obtained are examples of the practical application of advanced computational methods for determining and forecasting the ventilation risk in mine headings.

\section{Mathematical models}

The airflows at the maingate, tailgate and longwall are simulated as fully developed turbulent flow by using an $k-\varepsilon$ model.

\subsection{Basic flow equations}

System of balance equations of mass, momentum and energy (equations of fluid handling) of one-component flow takes the following form [8]:

$$
\begin{aligned}
& \frac{\partial}{\partial t}(\rho)+\operatorname{div}(\rho \vec{v})=0 . \\
& \frac{\partial}{\partial t}(\rho \vec{v})+\operatorname{div}(\rho \vec{v} \vec{v})= \\
& =\operatorname{div}(-p \overleftrightarrow{I}+\stackrel{\leftrightarrow}{\tau}+\stackrel{\leftrightarrow}{\tau})+\rho \overrightarrow{s_{b}} . \\
& \frac{\partial}{\partial t}(\rho \vec{v})+\operatorname{div}(\rho e \vec{v})= \\
& =\operatorname{div}\left[(-p \overleftrightarrow{I}+\stackrel{\leftrightarrow}{\tau}+\stackrel{\leftrightarrow}{\tau}) \vec{v}+\vec{q}_{s}+q_{s}\right]+\rho s .
\end{aligned}
$$

System of Eqs. (1-3) in a vector form can be written as [8]:

$$
\begin{aligned}
& \frac{\partial}{\partial t}\left(\begin{array}{l}
\rho \\
\rho \vec{v} \\
\rho e
\end{array}\right)+\operatorname{div}\left(\begin{array}{c}
\rho \vec{v} \\
\vec{v} \vec{v}+p \stackrel{\leftrightarrow}{I} \\
\vec{\rho} \vec{v}+p \stackrel{\leftrightarrow}{I} \vec{v}
\end{array}\right)= \\
& =\operatorname{div}\left(\begin{array}{l}
0 \\
\stackrel{\leftrightarrow}{\tau+\leftrightarrow R} \\
\left(\begin{array}{c}
\leftrightarrow m \\
\tau+\tau \\
\tau
\end{array}\right) \vec{v}+q_{s}+q
\end{array}\right)+\left(\begin{array}{l}
0 \\
\vec{\rho} \\
\rho s_{p}
\end{array}\right) .
\end{aligned}
$$

[8]:

Variables presented in the system of Eqs. (1-4) are

$$
\left\{\begin{array}{c}
\vec{v}, p, \stackrel{\leftrightarrow}{\tau}, \stackrel{\leftrightarrow}{\tau}, \vec{s}_{p}, e, s_{e}, \vec{q}_{s}, \vec{q}_{s}
\end{array}\right\},
$$

where: $\rho$ is the fluid density $\left(\mathrm{kg} / \mathrm{m}^{3}\right), \vec{v}$ is the air velocity $(\mathrm{m} / \mathrm{s}), p$ is the static pressure $(\mathrm{Pa}), \stackrel{\leftrightarrow}{\tau}$ is viscous molecular stress tensor $(\mathrm{Pa}), \stackrel{\leftrightarrow}{\tau}$ is turbulent Reynolds stress tensor $(\mathrm{Pa}), S_{b}$ is source of forces $\left(\mathrm{N} / \mathrm{m}^{3}\right), e$ is the sum of kinetic and internal energy $(\mathrm{J} / \mathrm{kg}), \stackrel{\rightarrow}{q}$ is molecular heat flux $\left(\mathrm{J} /\left(\mathrm{m}^{2} \cdot \mathrm{s}\right)\right), \stackrel{\rightarrow}{q}$ is turbulent heat flux $\left(\mathrm{J} /\left(\mathrm{m}^{2} \cdot \mathrm{s}\right)\right), S_{e}$ is sources of heat $\left(\mathrm{J} /\left(\mathrm{m}^{3} \cdot \mathrm{s}\right)\right)$.

The basis for a mathematical description of the transportation process of methane released into underground headings is the principle of mass conservation referred to this gas. The mathematical model of transportation, being a set of advection-diffusion equations, which for i- of this substance $i=1, \ldots . n$, assumes the following form [9]:

$$
\frac{\partial}{\partial t}\left(\rho Y_{i}\right)+\nabla \cdot\left(\rho v Y_{i}\right)=-\nabla \cdot J_{i}+R_{i}+S_{i}
$$

The flow of air stream through a longwall is a turbulent flow. This flow features irregular movements of the air stream particles, and the parameters of this flow undergo unpredictable random changes in space and time. A characteristic phenomenon for this type of flow is the occurrence 
of vortices of different sizes.

In the turbulence model $k-\varepsilon$, in the standard variation, the basic Navier-Stokes equation has been transformed into the Reynolds averaged equation. This equation includes an additional term in the form of the Reynolds stress tensor. Due to this term, the set of equations is not closed. To close the set of equations, it is necessary to introduce additional differential equations, which include the equation of kinetic turbulent energy and the equation of kinetic turbulent energy dissipation in the following form [9]:

$$
\begin{aligned}
& \rho \frac{\partial k}{\partial t}+\frac{\partial}{\partial x_{i}}\left(\rho k u_{i}\right)= \\
& =\frac{\partial}{\partial x_{j}}\left[\left(\mu+\frac{\mu_{t}}{\sigma_{k}}\right) \frac{\partial k}{\partial x_{j}}\right]+G_{k}+G_{b}-\rho \varepsilon-Y_{M}+S_{k}, \\
& \rho \frac{\partial \varepsilon}{\partial t}+\frac{\partial}{\partial x i}\left(\rho \varepsilon u_{i}\right)=\frac{\partial}{\partial x_{j}}\left[\left(\mu+\frac{\mu_{t}}{\sigma_{\varepsilon}}\right) \frac{\partial \varepsilon}{\partial x_{j}}\right]+ \\
& +C_{1 \varepsilon} \frac{\varepsilon}{k}\left(G_{k}+C_{3 \varepsilon} G_{b}\right)-C_{2 \varepsilon \rho} \frac{\varepsilon^{2}}{k}+S_{\varepsilon},
\end{aligned}
$$

where: $C_{1 \varepsilon}, \mathrm{C}_{2 \varepsilon \rho}, C_{3 \varepsilon}$ are constans, $\sigma_{k}, \sigma_{\varepsilon}$ are turbulent Prandtl numbers for $k$ and $\varepsilon, G_{b}$ is the generation of turbulence kinetic energy due to buoyancy, $G_{k}$ is the generation of turbulence kinetic energy due to the mean velocity gradients, $Y_{M}$ is contribution of the fluctuating dilatation in compressible turbulence to the overall dissipation rate, $S_{k}, S_{\varepsilon}$ are user-defined source terms.

\subsection{Constitutive equations}

A ternary species mixture comprising oxygen, water vapor and methane exists in the ventilation air in the mining headings. The interaction between the species is captured in the mixture density which follows incompressible ideal gas law given by [10]:

$$
\rho=\frac{p M}{R T}
$$

where: $R$ is the universal gas constant and $M$ refers to the mixture molar mass.

Mixture molar mass is given by:

$$
M=\left[\frac{\omega O_{2}}{M O_{2}}+\frac{\omega C H_{4}}{M C H_{4}}+\frac{\omega N_{2}}{M N_{2}}+\frac{\omega H_{2} O}{M H_{2} O}\right]^{-1}
$$

where: $M_{i}$ is the molar mass of species $i$.

Mass fraction of nitrogen is calculated as:

$$
\omega N_{2}=1-\left(\omega O_{2}+\omega \mathrm{CH}_{4}+\omega \mathrm{H}_{2} \mathrm{O}\right) .
$$

The air-methane mixture viscosity is calculated as:

$$
\mu=\sum_{i} \frac{x_{i} \mu_{i}}{\sum_{j} x_{i} \Phi_{i, j}}
$$

where: $x_{i, j}$ are the mole fraction of species $i$ and $j$ and:

$$
\Phi_{i, j}=\frac{1}{\sqrt{8}}\left(\frac{M_{i}}{M_{j}}\right)^{\frac{1}{2}}\left[1+\left(\frac{\mu_{i}}{\mu_{j}}\right)^{\frac{1}{2}}\left(\frac{M_{i}}{M_{j}}\right)^{\frac{1}{4}}\right]^{2}
$$

The mole fractions are related to the mass fractions by:

$$
x_{i}=\frac{\omega M}{M_{i}} .
$$

For practical purpose, methane concentration in terms is present of percentage of methane concentration, defined as $\mathrm{CH}_{4}=\omega_{\mathrm{CH} 4} \cdot 100 \%$.

\subsection{Methane emissions into the working area of the longwall}

It is very important for proper modelling of the entire flow process in the region examined to determine the amount of methane released into the longwall heading. This amount depends on a number of factors, the most significant of them being the methane bearing capacity of the seam, the height of the longwall exploited, the length and advance of the longwall, the duration of a mining cycle, and the speed of mining with a shearer.

The level of methane hazard at the exploitation stage is assessed by means of an analytical equation describing the criteria methane bearing capacity of the longwall [11]:

$$
\dot{V}_{k r y t}=\frac{c_{m-d o p} \cdot \dot{V}_{p s} \cdot k}{100 \cdot n}-\dot{V}_{D}, \mathrm{~m}^{3} / \mathrm{min}
$$

where: $\dot{V}_{k r y t}$ is the criteria methane bearing capacity $\left(\mathrm{m}^{3} / \mathrm{min}\right), c_{m-d o p}$ is the permissible content of methane in the used air flow discharged along the tailgate $(\%), \dot{V}_{p s}$ is the volumetric flow rate of air passing through the longwall $\left(\mathrm{m}^{3} / \mathrm{min}\right), k$ is the irregularity coefficient of air speed distribution in the longwall $(0.85), n$ is the irregularity coefficient of methane emission in the longwall region (1-1.55), $\dot{V}_{D}$ is the volumetric flow rate of methane reaching the longwall from other sources with the stream of fresh air $\left(\mathrm{m}^{3} / \mathrm{min}\right)$.

The volumetric flow rate of methane reaching the longwall from other sources was determined on the basis of the measurements taken in the streams of fresh air flowing to the longwall. This, in turn, served as the basis for determining the amount of methane flowing to the region examined, with the assumption that the volumetric flow rate of the air supplied to the longwall is equal to $1,380 \mathrm{~m}^{3} / \mathrm{min}$.

Based on the relationship (19), it was determined that $15.86 \mathrm{~m}^{3}$ of $\mathrm{CH}_{4} / \mathrm{min}$ will be released into the longwall.

\section{Problem statement and boundary conditions}

The purpose of the analysis was to identify the impact of airway geometry on the distribution of methane concentrations at the outlet from the longwall. In order to achieve this objective, a geometric model was developed for 
the longwall and the longwall headings as well as for the goaves with caving (Fig. 3).

In longwalls ventilated by means of the U-type system from the exploitation field borders, in order to dilute the methane concentration in the mixture with air, it is very common to use ancillary ventilation systems (a brattice with ventilation openings and an air duct). Such equipment was also used in the longwall in question. For this reason, the model developed also includes this equipment. A fragment of the geometric model of the intersection between the longwall and the airway, with the ancillary ventilation systems installed in the tailgate, has been presented in Figure 4. This figure also presents the geometric parameters of this area $(a-$ the length of the unliquidated part of the airway, $b$ - the location of the end of the ventilation brattice in relation to the liquidation line of the airway, $\mathrm{c}$ - location of the end of the air duct in relation to the liquidation line of the airway).

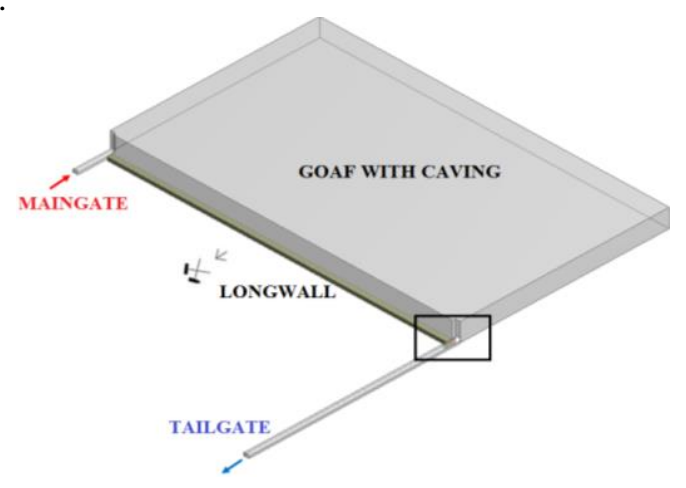

Fig. 3 The geometrical model

The tests were conducted for a longwall with a height of $2.3 \mathrm{~m}$ and a length of 230 metres. The longwall heading was 4 metres wide. The volumetric flow rate of the fresh air supplied to the longwall along the maingate amounted to $1,380 \mathrm{~m}^{3} / \mathrm{s}$.

The diameter of the additional air duct mounted in the maingate, along which additional fresh air was supplied at the rate of $440 \mathrm{~m}^{3} / \mathrm{s}$, was equal to $1.0 \mathrm{~m}$. The oxygen concentration in the air stream supplied to the longwall amounted to $21.0 \%$. The goaves with caving were 9 metres high and 110 metres long. For the purposes of the calculations, the flow of methane to the longwall and the tailgate was assumed to take place through the goaves and as a result of mining the body of coal. The ventilation methane bearing capacity for the longwall under examination was equal to $15.86 \mathrm{~m}^{3} / \mathrm{min}$. The other geometric dimensions of the region under examination for the four variants adopted for the analysis have been summarised in Table 1.

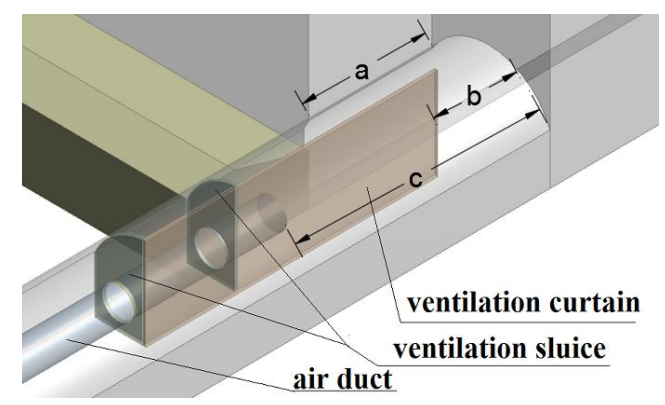

Fig. 4 The fragment of the geometric model of the intersection between the longwall and the airway, with the ancillary ventilation systems installed in the tailgate
The model so developed and the conditions adopted were analysed numerically.

Table 1

Geometric dimensions of the studied region and parameters of the air stream flowing through them

\begin{tabular}{|c|c|c|c|c|}
\hline & Case 1 & Case 2 & Case 3 & $\begin{array}{c}\text { Case } \\
4\end{array}$ \\
\hline $\begin{array}{l}\text { The width of longwall } \\
\text { galleries }\end{array}$ & $4.2 \mathrm{~m}$ & 3.6 & 4.2 & $4.2 \mathrm{~m}$ \\
\hline $\begin{array}{l}\text { The height of longwall } \\
\text { galleries }\end{array}$ & $3.2 \mathrm{~m}$ & $3.0 \mathrm{~m}$ & $3.2 \mathrm{~m}$ & $3.2 \mathrm{~m}$ \\
\hline $\begin{array}{l}\text { Lowering of the } \\
\text { longwall floor in rela- } \\
\text { tion to the tailgate floor }\end{array}$ & \multicolumn{4}{|c|}{$0.5 \mathrm{~m}$} \\
\hline $\begin{array}{l}\text { The length of the } \\
\text { unliquidated part of the } \\
\text { airway behind the cav- } \\
\text { ing line of the longwall } \\
\text { (a) }\end{array}$ & $4.0 \mathrm{~m}$ & $4.0 \mathrm{~m}$ & $2.0 \mathrm{~m}$ & $4.0 \mathrm{~m}$ \\
\hline $\begin{array}{l}\text { The location of the out- } \\
\text { let from the air duct in } \\
\text { relation to the liquida- } \\
\text { tion line of the airway } \\
\text { (c) }\end{array}$ & $8.0 \mathrm{~m}$ & $8.0 \mathrm{~m}$ & $6.0 \mathrm{~m}$ & $8.0 \mathrm{~m}$ \\
\hline $\begin{array}{l}\text { The location of the end } \\
\text { of the ventilation brat- } \\
\text { tice in relation to the liq- } \\
\text { uidation line of the air- } \\
\text { way (b) }\end{array}$ & \multicolumn{4}{|c|}{$2.0 \mathrm{~m}$} \\
\hline
\end{tabular}

\section{Results and discussion}

The calculations performed served as the basis for determining the distributions of methane concentration levels in the intersection area between the longwall and the tailgate (airway).

Fig. 5 presents the distributions of methane concentrations in the tailgate (at a distance of 2, 4, 6, 8, 10 and $12 \mathrm{~m}$ from the longwall caving line) for the four variants at hand.

The concentrations of methane for the models at hand in the planes presented are variable. Hence the scale illustrating the methane concentration level is adjusted to a specific plane.

The results obtained unambiguously demonstrate that the geometry of the tailgate and its length affect the distribution of methane concentrations in its cross section. Increasing the cross-section of the heading leads to a decrease in the maximum values of methane concentrations in this cross section.

The lowering of the longwall floor in relation to the tailgate floor impacts on the manner of distribution of the air flowing out of the wall and thus also on the local accumulation of methane present in the bottom part of the tailgate.

The phenomenon occurs in the tailgate with a cross sectional area of less than $10 \mathrm{~m}^{2}$. The local accumulation of methane in the bottom part of the tailgate during the outflow of air from the longwall does not occur for tailgates with a cross sectional area of over $12 \mathrm{~m}^{2}$.

The results obtained also allowed us to determine the values of methane concentration in a plane parallel to the longwall floor (in the horizontal plane). The distributions on a plane located at a distance of 1.5 metres from the floor for the computational variants analysed have been presented in Figs. 6 (cases 1 and 2) and 7 (cases 3 and 4). 
Case 1

Case 2

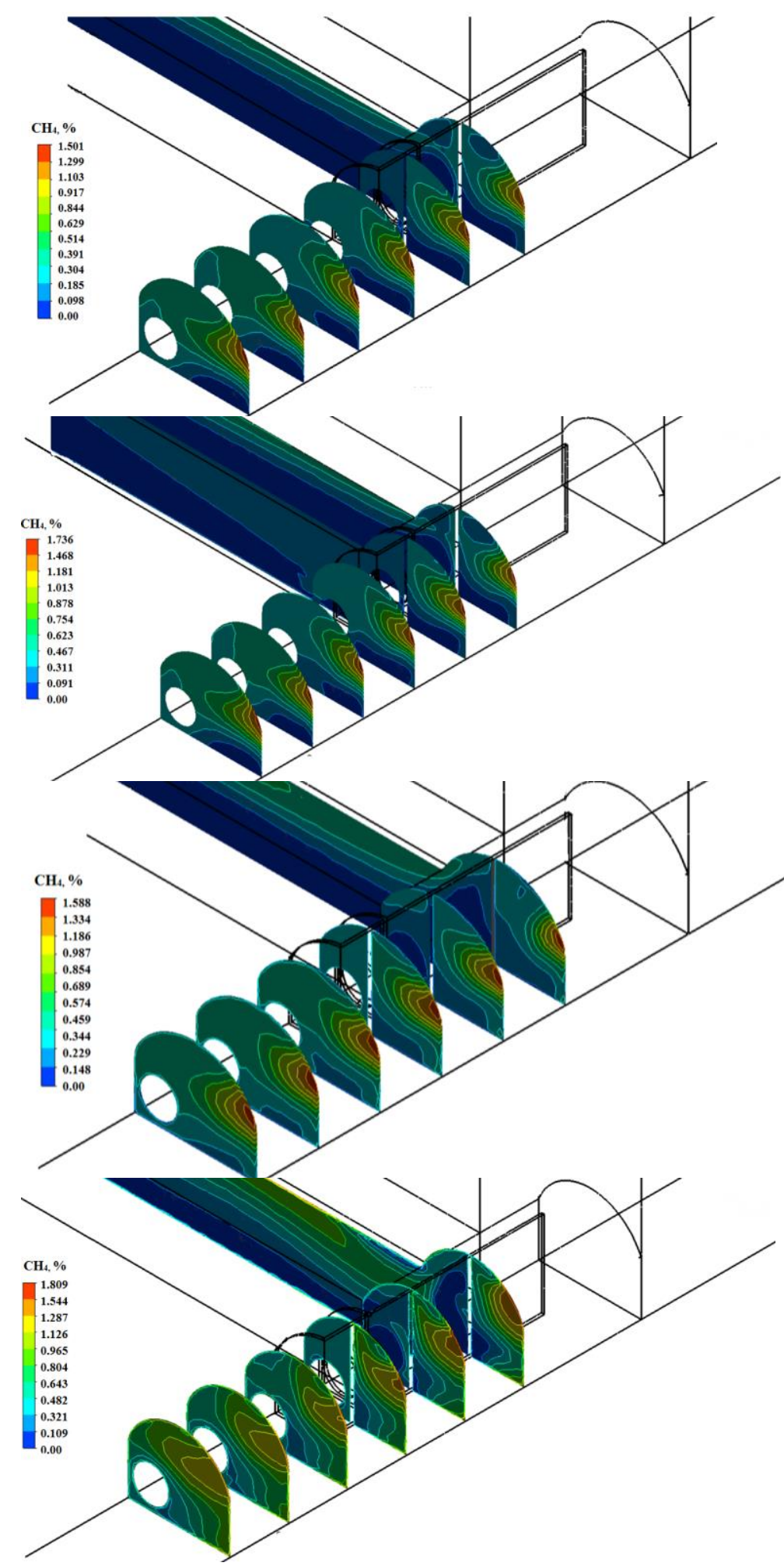

Fig. 5 The distributions of methane concentrations in the tailgate (at a distance of 2, 4, 6, 8, 10 and $12 \mathrm{~m}$ from the longwall caving line) for the four cases

Depending on the length of the unliquidated part of the tailgate and its transverse dimension, the differences in the distribution of methane concentration in the intersection area between the longwall and the tailgate result from the local changes in the distribution of air in the above mentioned intersection area, as well as from the lowering of the longwall floor in relation to the tailgate.

While considering the reach of the hazardous zone only in a horizontal plane located at a height of $1.5 \mathrm{~m}$ over the tailgate floor, one can conclude that the methane hazard grows in the region examined along with the reduction of the cross section of the tailgate to less than $10 \mathrm{~m}^{2}$. For variants 3 and 4, in which the cross sectional area of the tailgate amounted to more than $12 \mathrm{~m}^{2}$, the hazardous zone is limited only to a small part of the unliquidated tailgate behind the caving line.

Figs. 9-12 show the concentration levels of methane in the tailgate along the measurement line located at a distance of 2.8 metres from the tailgate floor. The measurement line has been marked in Fig. 8 . 


\section{Case 1}

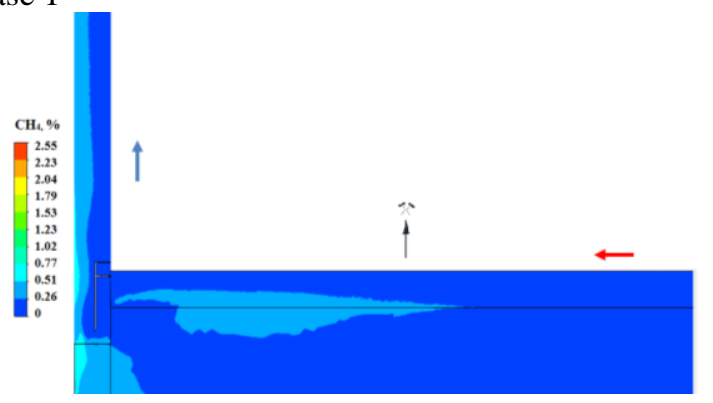

Case 2

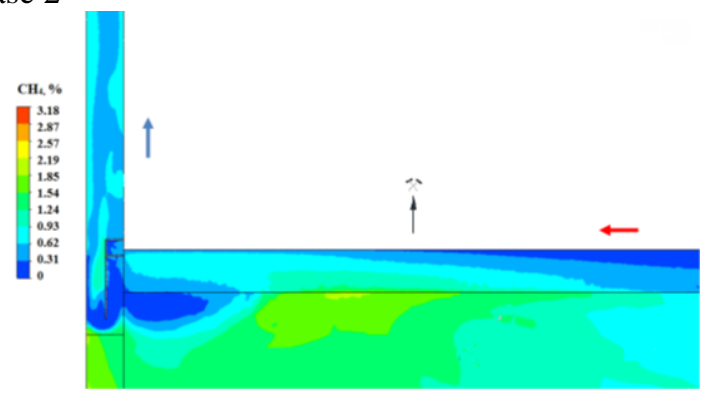

Fig. 6 The distributions of methane concentration in a horizontal plane at a distance of $1.5 \mathrm{~m}$ from the floor for cases 1 and 2

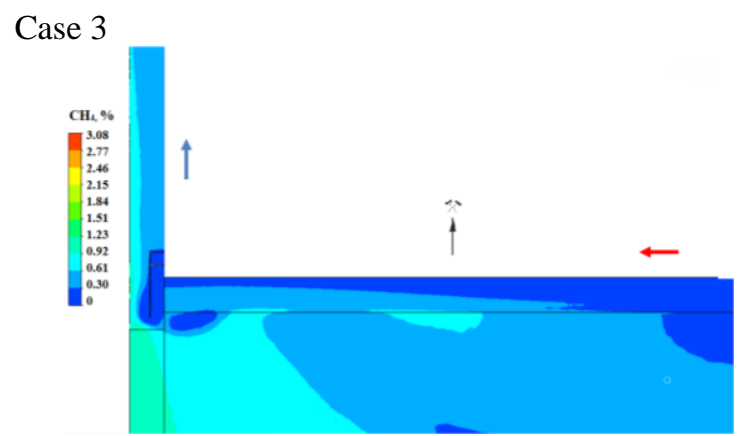

Case 4

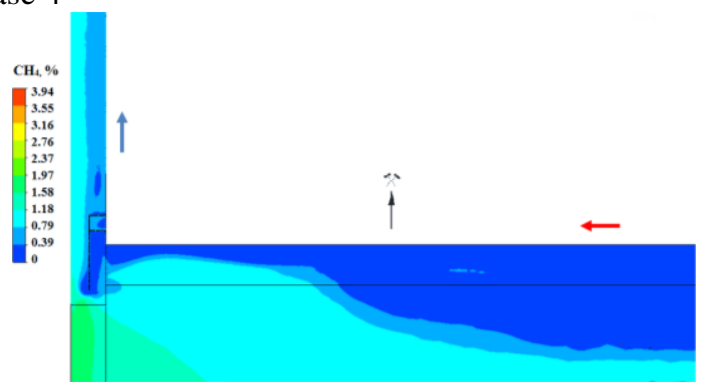

Fig. 7 The distributions of methane concentration in a horizontal plane at a distance of $1.5 \mathrm{~m}$ from the floor for cases 3 and 4

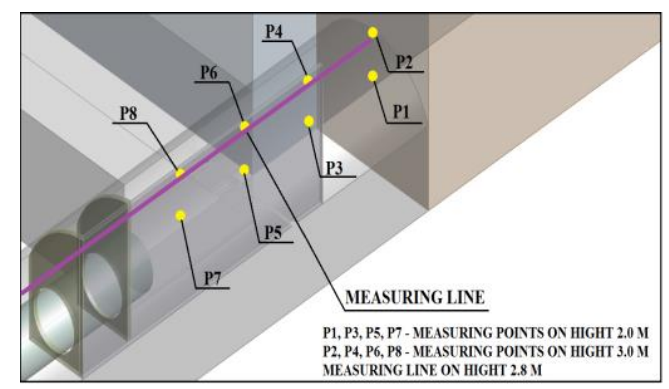

Fig. 8 Fragment of a geometric model with marked measuring points

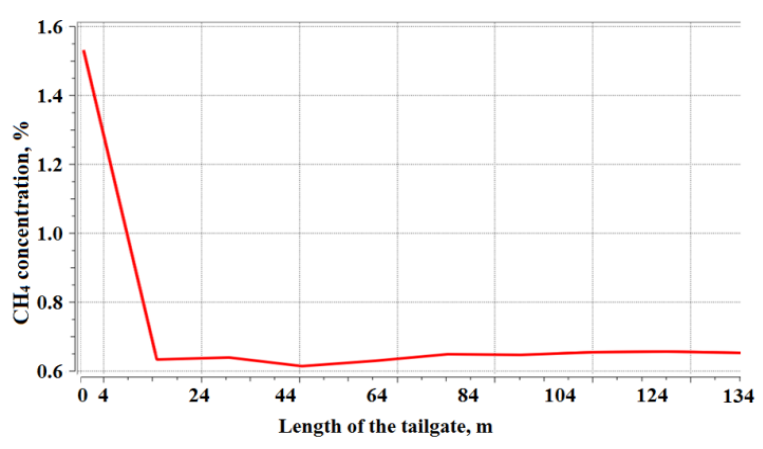

Fig. 9 The concentration of $\mathrm{CH}_{4}$ in the tailgate along the measurement line located at a height of 2.8 metres for case no. 1

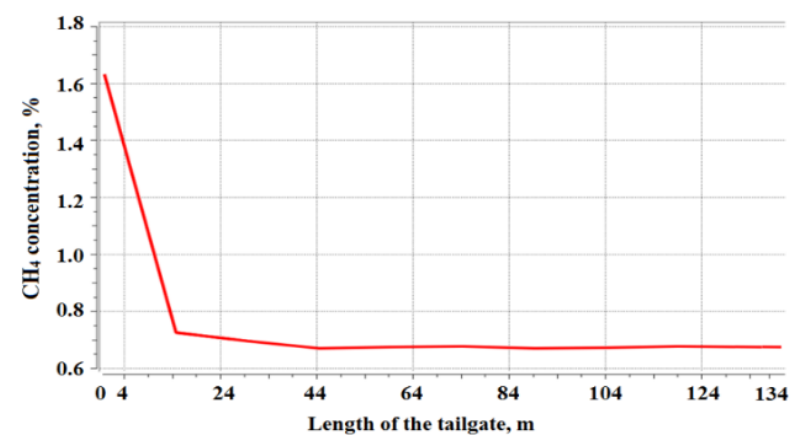

Fig. 10 The concentration of $\mathrm{CH}_{4}$ in the tailgate along the measurement line located at a height of 2.8 metres for case no. 2

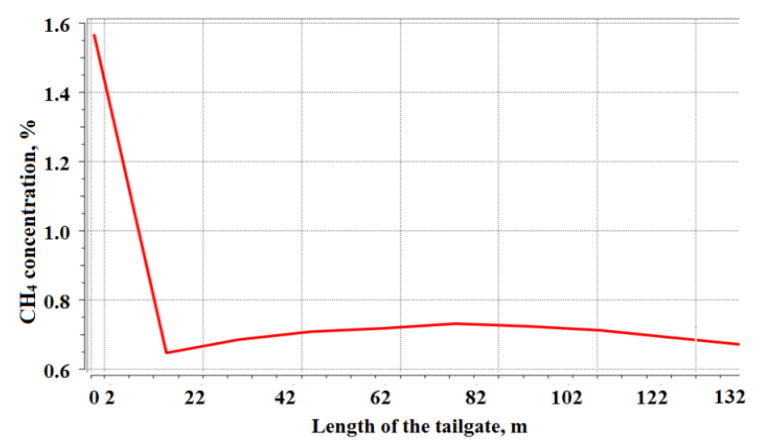

Fig. 11 The concentration of $\mathrm{CH}_{4}$ in the tailgate along the measurement line located at a height of 2.8 metres for case no. 3

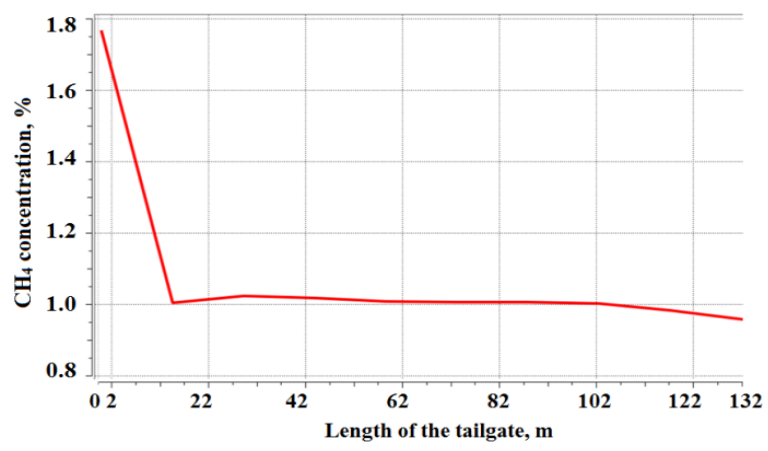

Fig. 12 The concentration of $\mathrm{CH}_{4}$ in the tailgate along the measurement line located at a height of 2.8 metres for case no. 4

Table 2 summarizes the determined values of methane concentration in the measuring points marked in Figure 8 (yellows points). 
Table 2

The values of methane concentration in the measuring points adopted

\begin{tabular}{|c|c|c|c|c|c|}
\hline Distance, $\mathrm{m}$ & Hight, $\mathrm{m}$ & Case 1 & Case 2 & Case 3 & Case 4 \\
\hline \multirow{2}{*}{$\begin{array}{l}\text { in the distance of } 2.0 \text { metres before the } \\
\text { caving line (P1) and (P2) }\end{array}$} & 2.0 & 0.69 & 1.23 & 0.91 & 1.65 \\
\hline & 3.0 & 0.79 & 1.67 & 0.94 & 1.71 \\
\hline \multirow{2}{*}{ concetration at caving line $(\mathbf{P 3})$ and $(\mathbf{P 4})$} & 2.0 & 0.84 & 0.98 & 0.91 & 1.03 \\
\hline & 3.0 & 0.97 & 1.04 & 1.01 & 1.10 \\
\hline \multirow{2}{*}{$\begin{array}{l}\text { in the distance of } 2.0 \text { metres from the cav- } \\
\text { ing line (P5) and (P6) }\end{array}$} & 2.0 & 0.41 & 0.74 & 0.52 & 0.81 \\
\hline & 3.0 & 0.71 & 0.91 & 0.86 & 0.95 \\
\hline \multirow{2}{*}{$\begin{array}{l}\text { in the distance of } 4.0 \text { metres from the cav- } \\
\text { ing line (P7) and (P8) }\end{array}$} & 2.0 & 0.21 & 0.36 & 0.28 & 0.39 \\
\hline & 3.0 & 0.29 & 0.51 & 0.30 & 0.57 \\
\hline
\end{tabular}

Based on the calculations performed, it can be concluded that the cross-sectional area of the heading and the length of the unliquidated part of the longwall heading behind the caving line have a significant impact on methane concentration levels in the particular points of its cross section. The concentration of methane in the measuring points decreases along with an increase in the cross-sectional area and the length of the unliquidated part behind the caving line. This is due to the growing volume of the heading, where methane is diluted by mixing with air.

\section{Conclusions}

The methane hazard is amongst one of the most dangerous phenomena in underground mining. When mixed with air in certain concentrations, methane becomes flammable and explosive. Therefore, in mining production, every effort is made to ensure that no dangerous concentrations of this gas occur during exploitation. In longwall headings, such a dangerous site is the intersection between the longwall and the tailgate. The measurements carried out in real world conditions and the results of model based tests presented in the paper substantiate this fact. Therefore, in order to ensure security for the crew members, it is necessary to develop a method for determining (estimating) the concentration of methane in this region as well as to identify the factors which may reduce this concentration.

The numerical model developed and presented in the paper satisfies these requirements. The use of real world measurement results in the calculations makes the findings more trustworthy. The universal nature of the model developed makes it possible to forecast the distribution of methane concentration for various geometric parameters of the heading and for many other variable factors.

The results of the multi variant analysis presented in the paper demonstrate that the geometry of the tailgate (its cross section and the length of its unliquidated part behind the caving line) has a significant impact on the values and distributions of methane concentration in the region under analysis. A change in the cross-section of the airway causes its ventilation capacity to deteriorate and the concentration of methane in this heading to increase at the junction of the airway and the longwall.

The results make it possible to conclude that a reduction in the cross section of the tailgate to less than $11 \mathrm{~m}^{2}$ has a significant impact on the increase in the methane hazard of this region. For the conditions present in this region, a safe cross section for this heading should therefore be greater than $11 \mathrm{~m}^{2}$. A significant role for the distribution of air in this region and, consequently, for the concentration of methane is also played by the presence and location of ancillary systems that considerably improve such distribution. It may be assumed that, through appropriate selection of mine heading geometry and application of additional ancillary systems, the methane related (and, in a wider sense, also the ventilation related) safety levels can be considerably enhanced in the region of mining exploitation.

The methodology, models and results presented in the paper exemplify the practical application of advanced numerical methods for identifying and forecasting the ventilation hazard in real world working conditions. In the Authors' opinion, the increasingly common practical application of scientific work results defines the right and acceptable direction for scientific research and analyses.

\section{References}

1. Brodny. J.; Tutak. M. 2018. Analysis of methane hazard conditions in mine headings, Tehnički vjesnik/Technical Gazette. 25(1): 271-276. http://dx.doi.org/10.17559/TV-20160322194812.

2. Tutak, M.; Brodny, J. 2017. Analysis of influence of goaf sealing from tailgate on the methane concentration at the outlet from the longwall, IOP Conf. Series: Earth and Environmental Science 95 (2017) 042025. http://dx.doi.org/10.1088/1755-1315/95/4/042025.

3. Ren, T. X.; Edwards, J. S. 2002. Goaf gas modeling techniques to aximize methane capture from surface gob wells. Mine Ventilation.

4. Kurnia, J. C.; Sasmito, A. P.; Mujumdar, A. S. 2014. CFD simulation of methane dispersion and innovative methane management in underground mining faces, Applied Mathematical Modelling 38: 3467-3484. https://doi.org/10.1016/j.apm.2013.11.067.

5. Branny, M. 2006. Computer simulation of flow of air and methane mixture in the longwall-return crossing zone, Archives of Mining Sciences 51(1): 133-145.

6. Krause, E. 2015. Short-term predictions of methane emissions during longwall mining, Arch. Min. Sci. 60(2): 581-594. https://doi.org/10.1515/amsc-2015-0038.

7. Regulation of the Minister of Economy of 28 June 2002 on occupational health and safety, operation and specialized fire protection in underground mining.

8. Sobieski, W. 2013. The basic closures of fluid mechanics in form characteristic for the finite volume method, Technical Sciences 16(2): 93-107.

9. Ansys Theory Guide, 2011.

10. Sasmito, A. P.; Birgersson, E.; Ly, H. C.; Mujumdar, A. S. 2013. Some approaches to improve ventilation system in underground coal mines environment - A computational fluid dynamic study, Tunn. Undergr. Sp. Tech. 34: 82-95. 
https://doi.org/10.1016/j.tust.2012.09.006.

11. Krause, E.; Lukowicz, K. 2000. Dynamic prediction of absolute methane emissions on longwalls (Technical guide).

J. Brodny, M. Tutak, A. John

THE IMPACT OF AIRWAY GEOMETRY ON THE DISTRIBUTION OF METHANE CONCENTRATIONS AT THE OUTLET FROM A LONGWALL

S u m m a r y

In underground hard coal mining, there are various types of natural hazards, which is related to human interference with the natural environment and the consequent disturbance of its equilibrium. The mining industry is an important component of the Polish economy, because coal is the basic raw material for power generation in the country.

Therefore, there are numerous tests and studies to make the mining activities safe and effective. As a result, a crucial role is played by research and scientific work that result in the improvement of safety in this branch of industry. One of the areas undertaken by such research is dedicated to limiting the methane hazard in mines. The underlying cause of this problem is methane release from the body of coal and excavated coal, because this gas is flammable and explosive. These properties place the methane hazard amongst one of the most dangerous mining phenomena.
The paper concentrates on the determination of methane concentrations in the area of ongoing exploitation, depending on airway geometry. The analysis is based on the model-based tests using computational fluid dynamics (CFD). The related calculations were performed by means of ANSYS Fluent based on the finite volume method (FVM). The analysis was conducted on a numerical model, reflecting the real-world region of the exploitation. The input data for the calculations were obtained from the results of measurements carried out in real-world conditions. The model developed takes into account a series of solutions that are the original scientific achievement of the Authors. This particularly refers to the modelling of goaves with caving as a porous medium. The calculations made it possible to determine the physical and chemical parameters of an air-methane mixture in each point of the region analysed. This is particularly true of the most dangerous area, namely the outlet from a longwall. In the case at hand, the calculations were carried out for several variants of airway geometry.

The methodology of model-based testing presented in the paper, taking into consideration the real-world measurements and the results obtained, is an example of how advanced calculation methods can be used for solving practical problems.

Keywords: methane hazard, geometry of mining headings, outlet form a longwall, CFD.

Received July 10, 2018

Accepted October 18, 2018 